\title{
Study on the Development of Sino Russian Trade Through Platform of Alibaba Express
}

\author{
Zhang Chen, Li Ning \\ Dezhou University \\ China Shandong 253023
}

\begin{abstract}
With the globalization of e-commerce deepening, Ali Express, Amazon and other international cross-border electricity business platform continue to improve and continue to grow and develop. At the same time, China's "one side of the road" macroeconomic policy, as well as Sino-Russian good-neighborly and friendly partnership in-depth development promotes bilateral trade and cross-border electricity business development,which provides a good opportunity. In this paper, we take Ali Express's Alibaba Express as an example, find its strengths and weaknesses, and take the use of speed to promote Sino-Russian cross-border electricity trade, to further promote the development of Sino-Russian trade to provide theoretical basis and strategy to stand by.
\end{abstract}

Keyword-Alibaba Express; Trade with Russia; Cross-border electricity providers

\section{INTRODUCTION}

In June 16, 2015, the State Council puts forwards "the guidance of the promotion of healthy and rapid development of cross-border e-commerce", which supports the development of cross-border e-commerce and is conducive to "Internet + foreign trade" to achieve superior and excellent, to play China's manufacturing power Advantages, to expand overseas marketing channels, and to promote the transformation and upgrading of enterprises and foreign trade. It will help to increase employment, promote public entrepreneurship, innovation, create new economic growth point; help accelerate the implementation of the "one way" and other national strategies to promote open economic development and upgrading [1]. At present, the rapid development of China's Internet and cross-border e-commerce has changed the traditional sales model and in this environment, the sale of the "international version of Taobao" continue to grow and develop. In particular, the speed of the sale of the Russian which provides a wealth of choices $t$ in the department store, clothing, daily necessities and other fields, as well as the increasingly perfect logistics system promotes Sino-Russian trade provides a broad prospect.

\section{THE AdVANTAGES OF ALIBABA EXPRESS IN SINO - RUSSIAN}

\section{TRADE}

"Ali Express platform" is a comprehensive platform for Alibaba to meet the global trend of e-commerce, global market, set orders, payment, logistics and integration of cross-border e-commerce B2C online transactions as an integrated platform. For the breakdown of Ali Express positioning in the domestic and international market differentiation, Alibaba Express B2C platform positioning targeted customers are foreign individuals, small and medium business owners and in the distribution business of small and medium-sized agents and distributors. After five years of promotion, Alibaba Express in the Russian market has begun to take shape. According to statistics, in the end of March 2013, more than 700,000 Russian users registered in the Alibaba Express platform account, accounting for about $9 \%$ of the total registered users. Therefore, although the pattern of global electricity business, Alibaba Express less than Amazon, ebay, but the Russian market, Alibaba Express have the incremental advantage which Amazon, ebay do not have [2].

Data show that cross-border electricity business in 2014-2015 increased by 30\% in import and export transactions, while the same period the national import and export transactions fell 7\%. In China's import and export trade, cross-border electricity business accounts for $14 \%-23 \%$ of the total trade volume and $39 \%$ of imports. Cross-border electricity business growth rate is 16 times the general trade, 7.3 times exports, 98 times the import. It can be found in the cross-border electric business advantage, driven by China's foreign trade has undergone enormous changes. Take Alibaba Express this ride, so that the relevant enterprises themselves to the high value-added chain on the integration. Cross-border electronics will be the future of new international trade development at home and abroad (see Table 1) [3]. 
Unit: trillion

\begin{tabular}{|c|c|c|c|c|c|c|}
\hline & $\begin{array}{c}\text { lump } \\
\text { sum }\end{array}$ & $\begin{array}{c}\text { Growth } \\
\text { rate }\end{array}$ & $\begin{array}{c}\text { Export } \\
\text { volume }\end{array}$ & $\begin{array}{c}\text { Growth } \\
\text { rate }\end{array}$ & Imports & $\begin{array}{c}\text { Growth } \\
\text { rate }\end{array}$ \\
\hline $\begin{array}{c}\text { import and } \\
\text { export }\end{array}$ & 26.43 & $2.3 \%$ & 14.39 & $4.9 \%$ & 12.04 & $-0.6 \%$ \\
\hline $\begin{array}{c}\text { Cross - border } \\
\text { electricity } \\
\text { providers }\end{array}$ & 3.75 & $39 \%$ & 3.27 & $36 \%$ & 0.48 & $59 \%$ \\
\hline$\%$ & $14.1 \%$ & $\begin{array}{c}16 \\
\text { Times }\end{array}$ & $23 \%$ & $\begin{array}{c}7.3 \\
\text { Times }\end{array}$ & $4 \%$ & $\begin{array}{c}98 \\
\text { Times }\end{array}$ \\
\hline $\begin{array}{c}\text { Cross - border } \\
\text { retail }\end{array}$ & 0.45 & $44 \%$ & 0.32 & $30 \%$ & 0.13 & $60 \%$ \\
\hline$\%$ & $12 \%$ & - & $10 \%$ & - & $27 \%$ & - \\
\hline
\end{tabular}

\section{THE DisadVANTAges OF Alibaba EXPRESS IN SINO -}

\section{RUSSIAN TRADE}

\section{A. High logistics costs, Long cycle}

At present, most of the Alibaba Express sellers have chosen "online delivery" or "independent delivery"

1) Online delivery refers to that the seller must first send items to the quick sell through the warehouse

The warehouse management is responsible for classification, unified distribution exit. The current Alibaba Express is through the global mobile warehouse, but only Shanghai, Shenzhen and Hangzhou three warehouses have. No matter which region, the state must first send the goods to China these three places, which will cause the additional expenditure.

2) Self-delivery is that Alibaba Express is through the seller through the local logistics services company to ship.

At present, most of the Alibaba Expressers sell their own shipments mainly through airbags or international express and aviation package is the most popular. Because compared with UPS, TNT, DHL, air bag charges are more cost-effective, allowing enterprises to save more costs. In the aviation package in the lowest fees, the most appropriate cost of transport is the Chinese postal packet, but the postal packet charges frequent changes caused by Alibaba Express business problems. In June 2013, the state fully raised the postal package charges. As the courier process cumbersome and cost is too high, it often appears that low-cost goods plus logistics charges after the price is much higher than the price of the goods themselves.

In May 2013, Speed Sold was adjusted for delivery of goods to Russia, which extends from 60 days to 90 days. Russian customs' seizure of goods for a long time is one of the main causes of long logistics cycle. According to statistics, in March 2013, Alibaba Express online sellers reach 110,000 and the parcel average daily sent to Russia is more than 40,000 pieces. Due to the limited number of Russian customs officers, the goods can not be dealt with in a timely manner, resulting in a large number of goods stranded. For small sellers, if Alibaba Express tong goods sent to Russia is increased to more than three months, it will be bound to cause cash flow problems and it is difficult to follow-up business.

\section{B. Electronic payment is difficult, the transaction security is difficult to protect}

As Alibaba Express cross-border e-commerce platform is a new product, so there is no right to sell through the platform authority and a complete legal system. So the platform for the sale of third-party cross-border payment and loan settlement still exists management loopholes and gaps, which increased cross-border electricity business funds revenue and expenditure difficulties and easily lead to the operation of the store's foreign exchange risk and shop funds and a series of problems. The current Russian e-commerce environment for electronic payment has not yet been fully formed. Because of its low market of electronic payment, low security factor of online transaction payment and imperfect information infrastructure, coupled with the relevant policies and legal system are difficult to protect, consumer awareness of online shopping is weak, with the local government policy, living habits, income level, religious awareness, education level, and some areas want to protect the local physical store so that they restrict or prohibit local staff cross-border online shopping, leading to the Russian trade electronic payment problem. 


\section{Use Alibaba Express platform to promote the}

\section{Sino-Russian trade talent scarce}

Innovation is the first driving force to lead the development, innovation is essentially driven by talent. China's cross-border electric business to expand the scope of the level of promotion can not be separated from the support of qualified personnel [4]. Cross-border electricity business in the early stages of development due to lack of policy caused by talent scarcity. The lack of technical personnel led to the operation of many shops and the quality of decoration without technical support and protection. The formation of cross-border electricity business in the number and scope of the continuous expansion, and the quality and level have not been improved situation. There are two reasons for this situation: First, the development and operation of the platform for the development and operation of the system is not perfect, the scale of talent and the advantages are insufficient, which affect the development of cross-border electricity business and shop business upgrade. Second, at the social level, there is no professional training institutions for cross-border electrician personnel and quick sales platform operators. More talent development can only be in the unconscious self-shallow level of development, the cross-border electricity business activities and shops cannot enhance and accelerate the efficiency [5].

\section{THE STRATEGY OF PROMOTING CROSS-BORDER}

\section{E-COMMERCE TRADE BETWEEN CHINA AND RUSSIA WITH}

\section{ALIBABA EXPRESS}

\section{A. Focus on improving the competitiveness of products}

Product homogeneity and price is the main factor that restricts the development of network operators. How to cater to the preferences of the Russian market, especially the taste of young Russian people, which is the first issue that should be considered. First of all, continue to innovate, bold development of a scientific and technological content and creative products and enhance the added value of products. Russian people are open, and like to highlight the personality, therefore, we should have a Chinese element and the Russian elements of the combination of products to be designed to attract the desire of the Russian people to buy. In addition to focus on improving product quality, they constantly build their own brand. In December 2015, Alibaba Express through the release platform settled in the new regulations, a substantial increase in the threshold of business settled, a comprehensive platform from the cross-border $\mathrm{C} 2 \mathrm{C}$ to $\mathrm{B} 2 \mathrm{C}$. This provision means to eliminate small sellers, focusing on supporting self-brand large business, thereby enhancing the visibility of our brand, influence and competitiveness.

\section{B. Improve the supply chain and logistics system construction}

Alibaba Express electricity business and the traditional foreign trade is the biggest difference between the traditional foreign trade enterprises, which is the first order, the production of goods delivery of goods, and speed is through the form of online stores to display products, products are produced well and adequate. Therefore, the product storage and logistics is the key to the cost of selling goods. In 2015, the Ministry of Commerce promulgated the "Internet + Circulation" action plan, pointed out that we will expand cross-border e-commerce, support the development of export enterprises, and construct a number of export products, "overseas warehouse" to further promote the development of foreign trade services. With the introduction of the plan, a lot of electricity business platform and export enterprises are through the construction of "overseas warehouse" to lay out the offshore logistics system. The establishment of overseas warehouses can allow export enterprises to bulk delivery of goods to foreign warehouses to achieve the country's local sales and local distribution. This new form of cross-border logistics is conducive to the development of cross-border e-commerce to meet the overseas terminal market demand for cross-border electricity, to meet the rapid implementation of orders to further enhance the integrated customer purchasing experience. From the practical operation, the export enterprises through the overseas warehouse direct local delivery can shorten the delivery time, reduce customs clearance, reduce transportation cost and improve the user shopping experience. Cross-border logistics related to transport, tools, commercial storage, tariffs, settlement and other issues, therefore, from the reality of cross-border electricity business, to create standardized, informative, professional logistics and distribution system, the establishment of distribution, transportation, storage integration the information platform, shorten the operation cycle. In addition, we should actively explore the establishment of overseas warehouses, and overseas Chinese market, cooperate with the Russian logistics distribution center and form overseas logistics centers and networks to enhance the distribution efficiency so as to achieve the purpose of reducing transport costs. "Overseas warehouse" will directly lead to consumer upgrades for China's cross-border electricity in Russia's trading volume to bring leaps and bounds. At the same time, "overseas warehouse" for the construction of China's electricity business in Russia provide a guarantee of after-sales service. "Overseas warehouse" Returns and after-sales service function significantly enhance the Russian buyers shopping experience for the Chinese electric business to establish a good reputation to provide a guarantee.

\section{Perfect the settlement system of the quick sell platform,}

diversified payment method, network transaction settlement convenience

In the Sino-Russian cross-border electricity trade, we must strengthen and improve the speed of the platform through the optimization and construction process, establish a standardized settlement system and a complete settlement system, establish a third-party cross-border payment management and standardization platform, straighten out Cross-border electricity shop business in the payment and settlement system to protect the relationship between third-party cross-border payment platform and ensure payment of security. At the same time, China-Russia cross-border electricity business in the trade should further deepen the strategic partnership, effectively reduce the settlement "recycling" in the process of 
mentioning the cost and expenditure, reduce store prices in the exchange rate fluctuations and freight cycle risks. In the foreign trade, electricity business is generally faced with different areas of settlement difficult environment, Alibaba Express platform for the development of Sino-Russian foreign trade should be based on the Russian market, take a variety of ways to pay coexistence. Opening the Russian consumer mainstream electronic payment platform such as Webmoney, Russian buyers can first recharge their own webmoney account, and then go to Ali Express's quick sell platform to buy goods, after the success of the seller things can be transported; for other parts of Russia, consumers should help develop the local electronic payment company, teach the local consumers to increase the network to pay security, to guide the Russian consumers to pay the network.

\section{Accelerate the training of high-level professionals for the}

\section{Sino-Russian cross-border electricity service}

In 2016, Alibaba International said to participate in international education through the "one hundred thousand schools" program, and cultivate 1 million students that have practical ability and are familiar with the credit security system with foreign trade knowledge in three years. At present, many local colleges and universities have the introduction of cross-border e-commerce professional classroom. Alibaba Express is through practice courses online communication to improve students' cross-border electricity business Russian negotiation in order to get the students to get more forward market information and the learning resources of the first hand platform . In order to promote the development of Sino-Russian trade cross-border electricity business and make full use of the platform for rapid sales, we must accelerate the development of the corresponding high-level talent. At the same time our company has introduced a large number of international vision that are familiar with international rules to participate in cross-border business store business and trade decision-making inter-disciplinary talent so that we can further make good use of the advantage of china-russia cooperation and high quality resources to satisfy the increasing of cross-border electricity demand.

\section{V.CONCLUSION}

The two countries are good-neighborly and friendly countries, under the impetus of the "area" initiative, improving the global Alibaba Express tong platform and promoting the development of international trade between China and Russia are of great significance to the development of the new-type sino-russian cross-border electricity [6].

\section{REFERENCES}

[1] Guiding opinions of the general office of the State Council on promoting the healthy and rapid development of cross border e-commerce, $[\mathrm{J}]$. Liaoning Provincial People's Government Gazette, 2015 (7): 80-80.

[2] He Xiaogang, Chen Yinping, Liu Keyao. "Alibaba Express of the Russian trade platform in the development of the problems and strategies" [J]. "Technology economy market", 2014 (2): 24-25.

[3] Wang Xiaoxuan, Xu Jia, Zhao Ningyu. A new channel for cross-border B2C export business platform - Take Ali fast selling pass as an example, [J]. modern business MODERN BUSINESS, 2016 (34): 50-51.

[4] "The innovation drive is essentially a human resource drive" $[\mathrm{J}]$. Chinese talent, 2014 (17): 4-5.

[5] Liu Shipeng. Analysis and Practice of Shop Operation of Cross-border Electricity Trading Platform [J]. Heilongjiang Science and Technology, Beijing, Heilongjiang, China) [7]: 114-145.

[6] Liu Jiaguo, Liu Wei, Liu Xiaoqi. Research on the development of cross-border e-commerce between China and Russia based on grounded theory method. Zhao Jin building, China soft science, 2015 (9): 27-40. 